Revista Mexicana de Economía y Finanzas Nueva Época

Volumen 14 Primer Número Especial Aniversario, Agosto 2019, pp. 559-582

DOI: https://doi.org/10.21919/remef.v14i0.423

\title{
Basel IV A gloomy future for Expected Shortfall risk models. Evidence from the Mexican Stock Market
}

Adrián F. Rossignolo ${ }^{1}$

University of Leicester, U. K.

(Recepción: 22/marzo/2019, aceptado: 25/junio/2019)

\section{Abstract}

To determine the sufficiency of Minimum Capital Requirements (MCR) in Basel IV during financial crises in the Mexican stock market, the paper performs a structural simulation encompassing both the Standardised (SA) and Internal Models Approach (IMA) employing different modelling techniques. The study finds an excessive increase in MCR even in abnormal slumps, furthermore stressing that SA establishes a high floor and only super-leptokurtic models are able to pass its stringent validation standards. Therefore, it is recommended that elements in SA be adaptable to avoid unnecessary capital largeness and the evaluation of the IMA and its interaction with SA revised. Although the outcomes strongly suggest the need to perform adjustments in the regulations, further tests on more markets could help bolster the results, despite the study ranking among the first to assess the adequacy and interplay between Basel IV's two approaches in Latin American emerging markets. The upshot indicates that Basel IV renders high MCR even for huge falls, placing models at a disadvantage and discouraging its use. The adoption of flexible calibration parameters would align both avenues, facilitating its application.

JEL Classification: G28, G38

Keywords: Basel IV, Capital Requirements, Standardised Approach, Internal Model Approach

\section{Basilea IV Un futuro sombrío para los modelos de riesgo de} déficit esperado. Evidencia del mercado de valores mexicano

\section{Resumen}

A fin de determinar la suficiencia de los Capitales Mínimos Regulatorios (MCR) de Basilea IV durante crisis financieras en el mercado mexicano, se propone una simulación estructural que abarca los enfoques Estandarizado (SA) y de Modelos Internos (IMA) basada en diversas técnicas. La investigación encuentra un incremento excesivo en MCR aún en situaciones de desplomes, enfatizando que SA establece mínimos elevados, mientras que solamente los modelos ultra-leptokúrticos superan las exigentes pruebas de validación. Se recomienda adaptar los parámetros de SA a diversos escenarios, de este modo evitando innecesaria sobreconstitución de capital y, posteriormente, revisar la evaluación de IMA y su interacción con SA. Aunque los resultados detectan la necesidad de ajustes en la normativa, pruebas adicionales en más mercados podrían reforzar las derivaciones, aún considerando que el artículo se encuentra entre los pioneros al momento de analizar el comportamiento y la relación SA-IMA en los mercados emergentes latinoamericanos. Basilea IV entrega altos MCR, incluso en movimientos anormales, colocando a IMA en desventaja y desalentando su desarrollo. La adopción de coeficientes de calibración flexibles alinearía ambos enfoques, allanando su aplicación.

Clasificación JEL: G28, G38

Palabras clave: Basilea IV, Requerimentos de Capital, Enfoque estandarizado, Enfoque de modelo interno

\footnotetext{
${ }^{1}$ Email: afr6@leicester.ac.uk

*No source of funding declared for research development
} 
REMEF (The Mexican Journal of Economics and Finance)

\section{Introduction}

In a statement in 2012, Andrew Haldane, Chief Economist and Executive Director of Monetary Analysis at the Bank of England, singled out the shortage of capital as one of the main motives that prevented banks and financial institutions to weather the financial crisis of 2007-2008 that led to the consequent controversial bailouts. Apparently, his view is shared by supranational regulators like the Basel Committee of Banking Supervision (BCBS), given the scale of the changes of Basel III with respect to its predecessor Basel II, particularly in key areas like market, credit and liquidity risks. However, even though the main objectives residing in strengthening the capital base and increasing the liquidity and credit risk provisions seem achieved, the Basel mandate is continually evolving.

Even though Basel III is still in implementation phase, in the meantime, the BCBS is reviewing its structure with a view to carry out some modifications to improve some departments, especially through a programme specifically directed to address market risks. Acknowledging the academics' opinion, the BCBS issued a document comprising the guidelines of the future Capital Framework with such depth that many practitioners ventured to call it Basel IV ${ }^{2}$ (Heltman (2014)). The Directive contains a radical overhaul to the capital ratio, risk weights and the two appraisals designed to compute the Minimum Capital Requirements (MCR): the SA and the IMA, which might be interpreted as a move away from the latter towards the former. The appearances suggest that the BCBS was suspicious of the banks' reliance on internal models and therefore demanded the implementation of different new standards imposing a much higher floor that may eventually result appropriate for some institutions but inadequate for others. The whole new regulatory body seems to be shifting away from a models-based structure towards an arguably easier scheme characterised by simpler and tougher capital ratios, combined with additional risk measures. Market-risk models, then, give the impression of being thrown into oblivion, thus obscuring their outlook.

It is precisely there where the motivations of the current study lie. Due to the extent of the new regulations, the opportunity to raise objections and to express the concerns is proper. Furthermore, as for the first time in the history of the supranational regulations the BCBS makes a distinction between developed and emerging markets, dealing with the latter to the detriment of the former adds an extra layer of interest in the novelty of the route taken here. Consequently, the article will be focused on and contribute to the financial literature carrying out a thorough quantitative evaluation of the prospective norms in the context of the Mexican emerging economy, carefully ascertaining the characteristics of the newly enacted SA and IMA (employing a considerable array of techniques); assessing the appropriateness of the capital floors and gauging the balance between the SA and the IMA. A perusal of the regulatory body suggests a crackdown on modelling, characterised by the stressed calibration for ES-based models accompanied by the stringent set of validation tests, which, coupled with the radical revamp of SA designed to hike minimum capital levels, lends to hypothesise that the future for models under Basel IV would look grim, possibly rendering them short of useless because of two potential reasons: a) their capital levels could exceed those of the SA by huge margins, or b) they may deliver capital levels smaller tan SA's but, although still sufficient enough to provide protection against huge market slumps, be ineligible on the grounds of situating below the official floor. The main objective, then, is to evaluate the test the appropriateness of the proposed regulations through the hypothesis of the disadvantageous position in which the theoretical assessment of the norms locate the modelling avenue; (if) and once it is determined, the paper will proceed to recommend straightforward alternatives to align

\footnotetext{
${ }^{2}$ The revolutionary scope of the alterations fosters the presumption that the financial industry might be in the doorstep of a new Basel Capital Accord, namely Basel IV. Therefore, the study will refer to it as Basel IV.
} 
Revista Mexicana de Economía y Finanzas Nueva Época, Vol. 14 Primer Número Especial Aniversario, pp. 559-582

SA and IMA and find a reasonable compromise that may allow banks to select between them instead of adopting a mandatory alternative.

The paper unfolds as follows. Section 2 synthetically outlines the basic notions underpinning the Basel IV reform, spanning the characteristics of the SA and the IMA and specifically emphasising the interaction between both approaches regarding the new floor embodied in the SA; Section 3 sketches a review of the literature that permits the location of the current study among the existing academic body and spot its distinctive elements that may contribute to the field; Section 4 explains the methodology that guided the study, from the construction of the portfolios to the calculation of the MCR and the respective validation standards; Section 5 details the results of the experiment from the regulatory stance and identifies the incentives (or, more precisely, the lack of) embedded into one or the other alternative and, furthermore, into the several possibilities belonging to the IMA and, finally, Section 6 provides the concluding remarks that reflect on the whole process and highlights the policy implications that the Basel IV framework might bring about stemming from its impact on the capital structure of the firms, simultaneously suggesting an alternative way -inside Basel platform- susceptible of remedying the imbalances found.

\section{The prospective Basel IV}

In spite of the fact that Basel III remains to be fully applied, the BCBS embarked on a thorough revision of the Basel III Capital Accord after realising that, in many respects, the Basel 2.5/III package "... did not fully address the shortcomings of the framework" (BCBS (2013)). In a series of Consultative Documents (BCBS (2012, 2013 and 2014)), the BCBS specified that the main areas of focus lay in: a) the trading book/banking book boundary, b) the treatment of credit, c) the approach to risk measurement, d) the incorporation of market illiquidity, e) the treatment of hedging and diversification, f) the relationship between the IMA and SA, and g) the comprehensive revision of the IMA and SA. In view of the strong bearing on the Pillar 1, namely the capital adequacy rules, the current article discourses on topics c), f) and g) where Basel IV brings, prior to any consideration about its adequacy, several radical changes compared with Basel III.

\subsection{A new approach to risk management}

The Consultative Papers of 2012 and 2013 highlighted two essential reforms which, alongside the rest of the proposals, would determine the shape of the new scheme:

a) Substitution of VaR (Value-at-Risk) for ES (Expected Shortfall): given the conceptual problems presented by VaR as a risk metric (Artzner et. al. (1999) and McNeil, Frey and Embrechts (2005), Danielsson and Zigrand (2006), among others), ES constitutes the official market risk measure for the IMA, calculated at $97.50 \%$ confidence level. Therefore, the replacement also signifies the demise of the $99 \%$ in favour of the $97.50 \%^{3}$;

b) Calibration to stressed conditions: The BCBS is postulating the adoption of an "indirect" approach to compute the ES over the observational period. Hence, in order to bridge the difficulties that the identification of a strained period could pose in terms of data availability for the full set of risk factors, banks should specify a reduced set of risk factors relevant for their portfolios for which a relatively long history of observations is available. Although banks are allowed to select the appropriate factors for their respective portfolios, the BCBS requires them to explain a pre-specified percentage of the full variation of the ES model ${ }^{4}$. Using that reduced set of factors, ES is

\footnotetext{
${ }^{3}$ More precisely, the VaR at $99 \%$ will not be employed for capital determination purposes; its usage seems restricted to the validation stage of the IMA.

${ }^{4}$ That percentage remains to be defined (BCBS (2013)).
} 
calibrated to the most severe 12-month stressed term available over the observation period and afterwards scaled up by the ratio of the current ES employing the full set of risk factors to the current ES utilising the reduced set of risk factors. Consequently, the risk capital calculation features the following expression:

$$
E S=E S_{R, S} x \frac{E S_{F, C}}{E S_{R, C}}
$$

where:

ES : Expected Shortfall for risk capital purposes

ESR,S : Expected Shortfall using the reduced set of risk factors calculated over the stressed period

ESF,C : Expected Shortfall using the full set of risk factors based on the current (most recent 12-month) observation period

ESR,C : Expected Shortfall using the reduced set of risk factors based on the current (most recent 12-month) observation period

\subsection{The relationship between the Standardised and Internal Mo- dels Approaches}

The BCBS proposes to reinforce the role of the SA as a feasible fallback to the IMA whenever these schemes are not appropriate for establishing regulatory capital. In that sense, banks must calculate the capital charge employing the SA in a bid to reduce the huge dispersion delivered by the present IMA techniques. The application of the SA as a capital floor could, in the eyes of the BCBS, ameliorate the pernicious influence of the most aggressive IMA assumptions.

Furthermore, a more rigorous process to ascertain the allocation of trading activities for the IMA, involves three steps:

1. Step 1: Overall assessment of the bank's firm-wide internal risk capital model using both qualitative and quantitative proofs (including Backtesting). At this stage banks should individualise the different trading units;

2. Step 2: Determination and evaluation of the specific trading activities (or trading desks) subject to the IMA. A three-pronged quantitative criteria involving Backtesting, Profits and Losses Attribution Tests (P\&LAT) and Model-independent risk assessment tool is to be employed to gauge the models's performance and behaviour;

3. Step 3: Following Steps 1 and 2, banks must identify which risk factors for each trading desk shall be included in the model.

Failure to comply with Step 1 indicates that the entire trading book does not qualify for the IMA and the SA has to be adopted instead; out-of-scope trading desks in Step 2 decrees the adoption of the SA, whereas non-modellable risk factors in Step 3 triggers the constitution of capital add-ons stemming from stress scenarios. Only after passing the three steps are banks allowed to compute the ES for the trading desks and their aggregation in a global ES with diversification constraints ${ }^{5}$.

\subsection{The comprehensive review of the Standardised and Internal Models Approaches}

The BCBS has put forward a thorough overhaul of both avenues in the most radical reform since the Market Risk Amendment of 1996 (BCBS (1996)).

\footnotetext{
${ }^{5}$ Desks falling or opting out of the IMA must use the SA for at least one year.
} 


\subsubsection{The revamped Internal Models Approach}

Once the bank has determined the eligible trading desks subject to the IMA, and provided it abides by the qualitative standards set by the BCBS (BCBS $(2013))^{6}$, the calculation of any model must contemplate a series of quantitative requirements. In this vein, the techniques must observe ${ }^{7}$ :

a) $97.50 \%$ one-tailed ES computed on a daily basis for regulatory capital purposes, both for the trading desks and firm-wide portfolios;

b) ES calibrated to a period of stress according to the "indirect" approach materialised in (2.1), with a sufficiently long sample for the reduced set of risk factors ${ }^{8}$;

c) $E S_{R S}$ estimated over the 12-month strained period in which the relevant portfolio experiences the greatest loss, with the observation horizon dating back to the year 2005 and its data sets, alongside those supporting $E S_{F C}$ and $E S_{R C}$ updated at least once a month or whenever market prices exhibit substantial variations;

d) Consistent with the VaR-based predecessors, BCBS does not prescribe a specific ES model for Basel IV, as long as the bank's technique captures all the material risks and passes the model validation standards (Section 2.3.1.1);

e) Analogous to Basel II and Basel III, banks must constitute a daily capital minimum requirement (MCRt) expressed $a^{9}$ :

$$
M C R_{t}=\max \left(I M C C_{t-1} ; m_{c} I M C C_{a v g}\right)
$$

where

$$
m_{c}=1,5(1+k)
$$

and

$I M C C_{t-1}$ : capital charge generated by the IMA for the previous day (t-1)

$I M C C_{\text {avg }}$ : average of the daily capital charges generated by the IMA for the preceding 60 days

$m_{c}$ : multiplication factor subject to an absolute minimum of 1.5

$k$ : add-on factor related to the ex-post performance of the model

It is important to state that in order to determine the value of $k$, banks must perform Backtesting following Basel II and Basel III for the full set of risk factors (using $\left.V a R_{F C}\right)^{10}$.

\subsubsection{Model validation standards}

Assuming the institution achieves the regulator's approval or passes Step 1 above, the evaluation of the eligibility of the trading desks demands a tough process involving ${ }^{11}$ :

\footnotetext{
${ }^{6}$ The qualitative demands refer, in broad terms, to the constitution of risk management calculation and control units, audit procedures and assessment tests (BCBS (2013)).

${ }^{7}$ The BCBS states some additional provisions regarding liquidity shocks. However, they lie outside the reach of the present paper.

${ }^{8}$ The length of the observation period is yet to be specified after subsequent Quantitative Impact Study (QIS), though the BCBS appears to be suggesting at least ten (10) years of history.

${ }^{9}$ The formula also comprises other components like the capital charge for positions subject to default risk and the capital charge for risk factors deemed unmodellable. However, they are purposefully skipped as they lie beyond the scope of the article. The interest reader may recur to BCBS (2013).

${ }^{10}$ BCBS $(2004,2009)$.

${ }^{11}$ The BCBS also proposes fourth criteria to assess the IMA applied, called "model independent risk assessment tool" involving the desk-level, ES-based MCR, the size of the exposure and a threshold, which is yet to be specified.
} 
a) Backtesting: it demands the comparison of the desk's daily static VaR at both $97.50 \%$ and $99 \%$ percentile applying at least one-year of the most recent data against the portfolio's actual P\&L. Models delivering more than 30 and 12 exceptions respectively detach the corresponding trading unit from IMA, sending it to capitalise under SA;

b) PELAT: they require the computation of two monthly tests:

I) P\&LAT1:

$$
P \& L A T 1=\frac{\frac{1}{n} \sum_{t=1}^{n}\left(P \& L_{t}^{T}-P \& L_{t}^{A}\right)}{\sigma\left(P \& L_{t}^{A}\right)}
$$

where

P\&LTt: theoretical (model forecast) P\&L for day t; $P \& L A t$ : actual P\&L for day $\mathrm{t}$

If the indicator situates outside the range $[-10 \% ;+10 \%]$, the trading desk experiences a breach, and four or more breaches in the last year means the trading desk has to employ the SA until it passes the P\&LAT and the associated ones.

II) PELLAT2:

$$
P \& L A T 2=\frac{\sigma^{2}\left(P \& L_{t}^{T}-P \& L_{t}^{A}\right)}{\sigma^{2}\left(P \& L_{t}^{A}\right)}
$$

If the ratio delivers values in excess of $20 \%$, the trading desk posts a breach, and four or more breaches in the most recent twelve months mean the trading unit falls under the SA until it passes the P\&LAT and the associated ones.

c) Risk factor analysis: Considering that the BCBS identifies the risk factors as interest rates, exchange rates, equity prices and commodity prices, banks must nominate a set of market prices and rates that drive the value of the respective positions for each risk factor, which should be sufficient to capture all the material risks ${ }^{12}$ affecting the portfolios. In this sense, the BCBS states that, for equity positions, market indices could constitute a reasonable method to encompass the fluctuations in stock prices ${ }^{13}$.

\subsubsection{The revised Standardised Approach}

The modification of the SA constitutes arguably one of the most radical innovations of Basel IV. Riding on the known concepts that the SA should provide a method to compute the capital base for those banks not in need of sophisticated risk models and, furthermore, act as a fallback to inadequate internal models, the appraisal appears hugely revamped following a "partial risk approach" resembling the classic portfolio theory (Markowitz (1952)), although with pre-specified risk weights and correlation parameters. In effect, instruments with similar risk patterns are grouped into risk buckets for which the BCBS affixes predetermined risk weights and, moreover, the hedging and diversification effects are seized by means of preset correlation factors.

Specifically, the capital charge for equity risk is obtained after the ensuing steps:

a) Step 1: allocation of net notional positions ${ }^{14}$ in the respective risk bucket according to a criterion that takes into account the size, region and sector of the company (Table

\footnotetext{
${ }^{12}$ The BCBS informs that the reduced set of risk factors must explain the movements in the portfolio.

${ }^{13}$ The Committee emphasises that, for instance, positions in individual stocks could be expressed in terms of the "beta-equivalents" relative to the corresponding market index. (BCBS (2013: 92)). Additionally, it stresses that banks are allowed to build more sophisticated approaches.

${ }^{14}$ The BCBS allows offsetting long and short positions on the same equity name, thus working with the net exposure.
} 
1). The boundary between "large" and "small" companies is established in a market capitalisation of USD 2 billion, and developed markets encompass the following ones: United States, Canada, the Eurozone, United Kingdom, Norway, Sweden, Denmark, Switzerland, Japan, Australia and New Zealand. Additionally, each bucket bears its own risk weight (Table 2). and the "Residual Bucket" gathers all companies that may not be allocated to buckets 1 to 10 because of data unavailability.

b) Step 2: application of the formula that acknowledges hedging and diversification within each risk bucket. Hence, for notional positions 1 to n:

$$
K_{b}=\sqrt{\sum_{i=1}^{n} R W_{i}^{2} M V_{i}^{2}+\sum_{i=1}^{n} \sum_{j>i}^{n} \rho_{i j} R W_{i} M V_{i} R W_{j} M V_{j}}
$$

where $R W_{i}, M V_{i}$ and $\rho_{i j}$ represent the risk weight assigned to position $i$, the value of the notional position $i$ and the correlation parameter between positions $i$ and $j$ respectively. $\rho_{i j}$ is established differently in accordance with the equity exposures bearing identical or opposite signs ${ }^{15}$ (Table 3 )

c) Step 3: explicit acknowledgment of the hedging and diversification across risk buckets. This last stage of the process allows the obtention of the Equity Risk Capital (ERC) by means of the aggregation of the risk positions for each individual risk bucket. Thus $(2.3 .5)$,

$$
\text { Equity Risk Capital }(E R C)=\sqrt{\sum_{i=1}^{B} K_{b}^{2}+\sum_{b=1}^{B} \sum_{c>b} \gamma_{b c} S_{b} S_{c}}+K_{\text {Residual }}
$$

where:

$K_{b}$ : capital requirement determined in $(2.3 .4)$

$K_{\text {Residual }}$ : capital requirement due to the residual bucket

$S_{b}: \sum_{i \in b} R W_{i} M V_{i}$

$\gamma_{b c}$ : correlation parameter between buckets b and $\mathrm{c}$, derived from the correlation matrix in Table 4.

\section{Literature review}

The issue of capital sufficiency has always been a contentious one and appears far from being settled, either from the regulatory or academic points of view. Even though the advent of the successive Basel Capital Accords allowed the amendment of the glitches in the previous regulations, the literature remains at odds regarding the virtues of the mandates. In this sense, while Caruana (2005) hails Basel II in view of its evolutionary aspects referred to implementation, calibration, validation and cross-border supervision, Repullo and Suarez (2013) question the procyclicality of Basel II. The authors go beyond, venturing to assert that Basel II bears more procyclical elements than Basel I, but, on the other hand, its capital levels turn banks into safer business units. The snags of Basel II become more evident in Herring (2005), who emphasises that the alleged gains from the adoption of Basel II are far outweighed by the costs of implementation and compliance.

The BCBS, performing its role as the supranational regulatory authority, typically employs the financial crises as a real time test to assess the adequacy of the Capital Accords, and, after proper consultation periods, and QIS, enacts partial or radical modifications to the existing order. However, it seems that it usually overlooks many important

\footnotetext{
${ }^{15}$ Identical sign refers to coincident long or short positions, whereas opposite sign denotes long and short exposures.
} 
implications; Demirguc-Kunt, Detragiache and Merrouche (2013) study a multicountry panel of banks before and after the subprime crisis of 2007-2008 and argue that different forms of capital exert different effects on the performance of the banks. Furthermore, they advocate the endorsement of higher forms of capital such as the Tier 1 and tangible common equity as alternatives to the BCBS's risk-adjusted capital ratio on the grounds of their relevance on the constitution of a stronger capital position.

After the 2007-2008 crisis and the consequent Basel 2.5 Amendment and Basel III Capital Accord, many authors commented on the patterns of the new regulations. Perhaps not surprisingly, the most stinging criticisms are referred to VaR, which application as a risk measure was bolstered in Basel III. From the seminal paper of Artzner et. al. (1999), $\mathrm{VaR}$ has been branded an 'incoherent' risk metric given its failure to comply with the subadditivity property that any risk measure must portray ${ }^{16}$. Furthermore, Artzner et. al. (1999) emphasise that VaR, by construction, can only estimate a quantile which does not enable it to inform about losses beyond that point. That alleged flaw prompted the BCBS to suggest other alternatives which may bridge those deficiencies like ES as well as other Spectral Risk Measures (SRM) (Acerbi (2004)), of which the former seems to be the BCBS's preferred choice.

ES has been extensively studied (Artzner et. al. (1999), Acerbi and Tasche (2002), Föllmer and Schied (2002), Yamai and Yoshiba (2005)) and branded as an intuitive and coherent risk measure. McNeil, Frey and Embrechts (2005) highlight that ES reverts the most notorious VaR's snags given that: i) ES always complies with the 'coherence' axioms established by Artzner et. al. (1999); ii) ES ameliorates the risk of selecting a particular confidence level as it represents the average of losses beyond that confidence level. This last property reveals especially important for regulatory bodies, which are undoubtedly concerned with shortfalls greater than VaR, i.e., losses posing risk to the financial health of the entity (BCBS (2012)).

Up to the so-called Basel IV ${ }^{17}$ Consultative Document, the BCBS had intended to remedy VaR's glitches with the introduction of several refinements, shaped in the enactment of the stressed VaR and the exogenously determined Capital Conservation and Countercyclical Capital Buffers (BCBS (2009)). However, instead of celebrating those amendments, the literature demanded the end of VaR-based models in the capital framework: Danielsson, Shin and Zigrand (2009) and Adrian and Shin (2013) opine that VaR accelerates the crises instead of halting their progress. Basel IV effectively replaces VaR for ES (BCBS $(2012,2013))$ in what constitutes a significant departure from the previous regulatory approaches to determine bank capital -both conceptually and procedurally-, a move partially suggested by Hellwig (2009) and Danielsson, Shin and Zigrand (2009). However, in addition to the most renowned snags referred to the IMA that the BCBS intends to tackle (BCBS (2013)), it remains to be evaluated whether the inception of $\mathrm{ES}$ as the official market risk measure reduces the alleged VaR 'manipulation' that may enable banks to erect lower capital requirements, as highlighted by Hellwig $(1995,1996)$ and Danielsson and Zigrand (2006), though the latter make use of derivatives.

The BCBS took special care in strengthening the process of evaluating the capital estimation; in addition to the qualitative considerations, Backtesting and Stress tests contained on Basel III, a new battery of tests is proposed. Hence, admitting the difficulty in backtesting ES in view of its inherent structure (Kerkhof and Melenberg (2004)), the BCBS improves the current framework keeping an enhanced VaR-based Backtesting ("Breach test") and adding two P\&LAT, which are designed to attest whether VaR models

\footnotetext{
${ }^{16}$ Danielsson et. al. (2005) and McNeil, Frey and Embrechts (2005) were able to find some instances where VaR could achieve subadditivity. However, they stress that those examples constitute asymptotic results for nonsensically high confidence levels, irrelevant in practice.

${ }^{17}$ For the sake of simplicity, the current article will denote as Basel IV the proposals contained in the documents that review the market risk framework (BCBS $(2012,2013)$ ).
} 
Revista Mexicana de Economía y Finanzas Nueva Época, Vol. 14 Primer Número Especial Aniversario, pp. 559-582

keep track of the variations in the dynamic properties of risk as demanded by Berkowitz and O'Brien $(2002)^{18}$.

The BCBS maintains its stance at the time of dealing with the schemes within the IMA as there are no specific indications on that respect. Consequently, all the techniques developed by the practitioners might in principle be applied to estimate ES, much in the same fashion than in Basel II and Basel III; in this vein, alternatives like Historical Simulation (Manganelli and Engle (2001), Dowd (2005)), Filtered Historical Simulation (Barone-Adesi, Bourgoin and Giannakopoulos (1998), Boudoukh, Richardson and Whitelow (1998)), Conditional Volatility (McNeil, Frey and Embrechts (2005), Alexander (2008), Engle (1982), Bollerslev (1986), Taylor (1986), Nelson (1991)) and Extreme Value Theory (Embrechts, Klüppelberg and Mikosch (1997), McNeil and Saladin (1997), McNeil, Frey and Embrechts (2005), Coles (2001), Reiss and Thomas (2007)) are available, among many others (Christoffersen (2003), Alexander (2008)). The fitting prowess of the representations remain to be analysed, particularly in the event of major crises (which constitute the BCBS's major concern), although Rossignolo, Fethi and Shaban (2012, 2013) show that highly leptokurtic models could -under certain circumstanceshave prevented banks from falling into bankruptcy to the point of avoiding the more stringent Basel III regulations.

The SA has also been subject to a major revamp under Basel IV proposed reform in order to achieve the major objectives outlined by the BCBS (2014) materialised in: providing an alternative methodology for banks not qualifying for the IMA, finding a credible fallback for models and, finally, facilitating the comparison of capital levels across borders. In this sense, the BCBS put forward a sensitivity-based approach that resembles the Markowitz framework (1952), although the market correlations are prescribed by the BCBS. The BCBS (2014) nonetheless informs that market participants were demanding the ditching of the flat rate characteristic of Basel II and Basel III in favour of a more market oriented appraisal.

The issue of capital sufficiency, finally, has always been subject to heated controversy, particularly because of its close connection with the regulatory requirements, given that banks usually tend to adjust their capital buffers in such a manner that they only exceed the minimum levels by a small margin (Berger et. al. (2008)). Consequently, the adequacy of the capital framework acquires utmost relevance and, consequently, it is not surprising to find opposing views: from Haldane (2011) who underlines the complexity and lack of robustness of the regulatory structure which augments the model error in the IMA and the ensuing inappropriateness of the capital ratios, to the staunch support of the countercyclical capital buffers in Shim (2013) and the criticism launched by Rossignolo, Fethi and Shaban (2013) who question the application of Basel III and propose the utilisation of Basel II with highly leptokurtic models, as well as a complete revision of the SA.

The current article contributes to the literature from different angles, with reference to the new proposals susceptible of being labelled Basel IV: in the first place, it targets the quantification of the introduction of ES in the respective settings for the estimation of MCR using a variety of models (IMA) in comparison with the analogous requirements in Basel II and Basel III; in the second place, it critically evaluates the numerical relationship between the ES-based IMA and the market sensitive SA assessing the incentives to develop accurate internal models and, in the third place, it fosters the suitable and (easily) applicable calibration remedies in order to align incentives, specifications and capital buffers between IMA and SA.

\footnotetext{
${ }^{18}$ It is important to emphasise that stress tests are also part of the assessment structure of Basel IV (BCBS (2013)).
} 


\section{Methodology}

To assess the impact of the new proposals on the banks' capital base, the present paper works on long stock portfolios comprising Mexican companies. For the sake of simplicity and tractability, two classes of three asset portfolios are constructed: Portfolio 1 -equally weighted- and Portfolio 2 -minimum risk- ${ }^{19}$, and firms are selected and allocated pursuing data reliability and consistency employing primary data extracted from Thomson Reuters $(\mathrm{B})$ and finally applying Basel IV criteria referred to the allocation in terms of 'large' or 'small' firms ${ }^{20}$ (Table 5, Columns [8-9]).

IMA and SA allow the determination of capital levels. With regards to the former, the article employs Historical Simulation (HS), Filtered Historical Simulation (FHS) featuring GARCH and EGARCH specifications appended by Normal and Student-t distributions (FHS/GN, FHS/EN, FHS/Gt and FHS/Et), Conditional Volatility (CV) encompassing GARCH and EGARCH techniques estimated with Normal and Student-t distributions $(\mathrm{CV} / \mathrm{GN}, \mathrm{CV} / \mathrm{EN}, \mathrm{CV} / \mathrm{Gt}$ and $\mathrm{CV} / \mathrm{Et})$, Extreme Value Theory (EVT) via Peaks Over Threshold (POT) after GARCH-Normal pre-whitening (Embrechts et. al. (2005)) as well as the so-called Linear schemes (enhanced by Normal and Student-t distributions) as indicated by Penza and Bansal (2001). All IMA representations are afterwards tested applying the preceding Steps 1 to 2 (Backtesting and P\&LAT), whereas, Step 3 (Risk Factor Analysis), Portfolios 1 and 2 from every country are mapped to the respective market index and the resulting $R^{2}$ calculated $^{21}$.

The paper proceeds comparing the ERC arising from every (validated) IMA with that surging from the SA for both portfolios in a bid to gauge the pertinence of the corresponding levels. Furthermore, the contrast between the MCR belonging to Basel's IV most accurate IMA and SA with Basel's III MCR using the same models, conveys an idea about the profundity of the modifications contained in Basel IV.

Finally, the article proposes some straightforward routes to solve the likely problems that may arise because of the disparity in the capital levels derived from IMA and SA, furthermore contributing to deal with the incentives problem that -again- appears in Basel IV. The paper bolsters the use of a series of calibration parameters that contribute to level the Loss Coverage Ratio (LCR) across the approaches.

\section{Results}

The outcome of Basel IV methodology displays several differences compared with its predecessor Basel III, from the validation process that the IMA appraisal is subject to the behaviour of the SA.

\subsection{Basel IV validation process}

Table 6 (Panels A and B) depicts the result of the Backtesting, carried out at $99 \%$, following Basel II and Basel III procedures and, while Panel A reports the quantity of exceptions, Panel B indicates the penalties envisaged as a result of the test. In this sense, it is not surprising the failure of HS and the Linear (Normal and Student-t) specifications to pass Backtesting. Reliance on the Normal distribution appears to affect CV models (GARCH and EGARCH) more than FHS ones (EGARCH), whilst the Student-t distribution improves the performance only for CV models. Given that the rest of the schemes pertain to the Yellow Zone (i.e., bear some sort of penalty), a closer examination of Ta-

\footnotetext{
${ }^{19}$ The minimum risk portfolio is calculated according to the Mean Variance Criterion (MVC), i.e, following Markowitz's (1952) guidelines. It is acknowledged that, among the many ways to construct portfolios, those utilised belong to the most renowned ones.

20 'Large' firms report market capitalisation equal to or over USD 2 billion.

${ }^{21}$ Even though Basel IV does not specify which $R^{2}$ value could qualify as significant, the current paper will validate $R^{2}$ figures about 0.50 , tantamount to expressing that the index explains at least $50 \%$ of the variations in the value of the respective portfolios.
} 
Revista Mexicana de Economía y Finanzas Nueva Época, Vol. 14 Primer Número Especial Aniversario, pp. 559-582

ble 6 Panel B suggests the notion that, in principle, the empirical distributions produce smoother estimates than the theoretical Normal or Student-t, reflected in the surcharges envisaged for CV models. Finally, EVT manages to deliver outstanding results with no exceptions and, therefore, does not require additions to the capital base due to higher $\operatorname{VaRs}^{22}$.

Tables 7 and 8 -Panels A and B- inform the outcome of the first part of the second stage of the evaluation process contained in Basel IV. In that respect, Panels A and B of Table 7 evince the exceptions recorded at $99 \%$ and $97.50 \%$ whereas Panels A and B of Table 8 report whether the models are susceptible of being utilised ${ }^{23}$. The comparison of Panels A and B of Table 8 shows that the BCBS achieves coherency at the time of establishing the boundaries for each confidence level as the absence of discrepancies reinforces the outcomes obtained (Table 9). The second step of the second stage involves the newly enacted P\&LATs, P\&LAT1 and P\&LAT2 (as expressed in formulas 2.3.3 and 2.3.4. above). Tables 10 and 11 -Panels A and B- exhibit the quantity of breaches recorded in the Backtesting period and the specification that would be used to capitalise the trading desk for each test respectively. Table 12 shows the result of the whole Step II (Stages 1 -Backtesting- and 2 -P\&LAT1 and P\&LAT2-), where it may be appreciated that all FHS techniques for both portfolios are given the all clear. As aforementioned, EVT again passes Step II with flying colours.

Table 13 exposes the outcome of Steps 2 and 3 of the validation process, which blends Basel II and Basel III's Backtesting with Basel IV's Steps 1 and 2. The display conveys the idea of a much more rigourous approach on the part of the proposed new Capital Accord, arguably due to the establishment of the Step 2 (further Backtesting and P\&LATs). In that respect, only a handful of specifications would be allowed as IMA in selected countries: nearly all FHS models (except FHS/EGARCH-T in P2), CV/GARCH-t and EVT. However, the associated analysis of Table 6 and Table 13 crowns EVT as the most reliable model as it does not take any penalty under Stage I (former Basel Backtesting) and, additionally, weathers Step 2 without any exclusion. This result should not be labelled as surprising, although the novelty in this occasion resides in the fact that the methodology circumvents the prospective Basel IV more stringent criteria. In view of the aforementioned reasons, and considering its untainted performance, the rest of the article employs the EVT-based model in the issues connected with capital levels and its interaction with the SA and further relationships.

Step 3 deals with the identification of the risk factors to be included in the capital calculation formula under $E S_{R C}$ and $E S_{R S}$ in formula (2.1). As expressed in 2.3.1.1. c) above, the BCBS (2014) suggests that with regards to equity exposures, an equity index would, in principle, suffice the construction of a reduced risk-factor model provided it explains the movements of the portfolio with a degree of accuracy embodied in a (high) value of the $R^{2}{ }^{24}$. In this vein, the blue-chip index (Table 14 Column [3]) may reasonably approximate the movement of the portfolios as the $R^{2} \mathrm{~s}$ situate on or above the $50 \%$ threshold (Table 14 Column [4]), presumably granting approval for the usage of the corresponding IMA.

\subsection{Basel IV Capital Levels}

Table 15 depicts the MCR arising from all the models, calculated for both portfolios. Unfortunately, the question of the adverse incentives to employ the most accurate techniques underlined by Rossignolo, Fethi and Shaban (2013) in Basel III hovers around in Basel IV

\footnotetext{
${ }^{22}$ Quite surprisingly, the prospective Basel IV documents do not state clearly whether models failing Basel III Backtesting are disqualified although it would appear sensible to act that way.

23"IMA" and "SA" mean that the scheme registers less and more than 12 and 30 exceptions at $99 \%$ and $97.50 \%$ respectively.

${ }^{24}$ Although the exact value of that $\mathrm{R} 2$ is not defined yet, the document hints at 'high enough' figures.
} 
too, given the fact that models with unblemished reputation can still deliver MCR higher than penalised ones. In this vein, a simple comparison of the MCR that the two of the representations capable of overcoming the validation process (for instance, CV/GARCH-t and EVT) shows that in some occasions the former suffers Backtesting penalties (Step 1) and still manages to constitute lower MCR than the latter (Table 6 Panel B and Table 15): $\mathrm{P} 1(\mathrm{k}=50 \%)$ and $\mathrm{P} 2(\mathrm{k}=85 \%)$. However, the figures offer some consolation in terms of the incentives because CV/GARCH-t appears capable of producing the smallest MCR among all those techniques that pass Basel IV validation process (Table 6 Panel B and Table 15), thus signalling the healthy intention to provide right accuracy incentives.

Much in the same fashion as in Basel III, Table 15 Column [11] beckons the somewhat excessive amount of capital buffers that an institution resorting to EVT may be compelled to constitute. Even though that situation is consistent with the main characteristics of the theory, the values reported seem nevertheless relatively high for the purposes intended, which might result dampened following the procedures suggested in the ensuing paragraphs. On the other hand, the fact that Basel IV relies on ES for the estimation of IMA-based EVT does not automatically induce the constitution of higher MCR, compared with Basel III's VaR-based MCR as Table 16 Panel A, Columns [2-4]. It may be appreciated that the influence of the addition of the stressed VaR in Basel III as opposed to the ratio scheme courtesy of Basel IV plays a role not to be neglected and may potentially help to explain the reasons behind a VaR-based formula exceeding an ES one (Table 16 Columns [2-4]).

As aforementioned, the SA also suffers major restructuring, crystalised in the (more than) duplication of the MCR (Table 16 Panel A, Columns [6-7]). The approach taken by the BCBS in Basel IV should represent a huge step forward, both in the capital levels and in the derivation of the ERC from expression (2.3.5). Notably, the establishment of fixed risk weights and correlation parameters produces very stable and uniform ERC (Table 16 Panel A, Column [6]) with a stunningly low standard deviation of $0.91 \%$ as contrasted with the $1.91 \%$ delivered by the IMA-EVT ${ }^{25}$. In principle, the MCR obtained through the SA would prove sufficient to withstand crisis of significant magnitudes and, furthermore, raise the capital floor to considerable minimum levels, therefore achieving one of the BCBS's most pressing concerns.

\subsection{Interaction between IMA and SA}

The relationship between the revised IMA and SA undoubtedly comprises one of the aspects of the utmost relevance to evaluate the extent of the revamp. Accordingly, Table 16 Panel A informs the comparison between the MCR calculated employing Basel III's and Basel IV's SA and IMA via EVT.

Unsurprisingly, EVT delivers higher MCR than the SA across the board both under Basel III and Basel IV configurations (Table 16 Panel A, Columns [2-7]); however, due to the thorough review carried out on the SA, the gap between the most accurate IMA version and SA shrinks ostensibly from $+677 \%$ to $+25 \%$ (average terms) respectively (Table 16 Panel A Columns [8] and [9]), thus fulfilling the BCBS's declared aim of overhauling the SA and hinting at the insufficiency of the equity base provided by the SA during market turbulence. Furthermore, the $246 \%$ growth in the SA capital buffer, compared to the decrease of $44 \%$ (average figures) of the IMA (Table 16 Panel A, Columns [4] and [7]) gives credit to that notion despite the introduction of ES and the inclusion of the stressed ES in (2.1).

The crusade of the BCBS to raise the MCR by setting substantially higher capital floors could be grasped glancing at Table 16 Panel B, which deploys the Basel IV MCR computed with the SA and the model contributing with the lowest MCR, i.e.,

\footnotetext{
${ }^{25}$ Acknowledging the volatility in the estimation of the Generalised Pareto Distribution (GPD) characteristic of the EVT (Reiss and Thomas (2007)).
} 
Revista Mexicana de Economía y Finanzas Nueva Época, Vol. 14 Primer Número Especial Aniversario, pp. 559-582

$\mathrm{CV} / \mathrm{GARCH}-\mathrm{t}$. Overlooking the limitations of average values, the overall MCR provided by the SA exceed those by the IMA by $4 \%$ approximately (Table 16 Panel B, Column [4]). Moreover, the effect of the rise of the floor (". . credible fallback. ..", BCBS (2014)) embodied in the SA appears plainly reflected in Table 16 Panel B, Column [6]), given that in 1 out of 2 cases $(50 \%)$, the MCR correspond to the floor, i.e., SA, instead of the IMA, which means that in half of the portfolios the amount delivered by the $\mathrm{CV} / \mathrm{GARCH}$ - $\mathrm{t}$ situates below the SA.

\subsection{The gloomy future for market risk models}

On the grounds of the examples, the interaction between the IMA and the SA in Basel IV poses a gloomy future for the models in the sense that those prospective regulations do not seem to provide enough incentives to make use of the IMA-ES avenue to calculate the MCR. The extent of that plight is conveyed by Table 17, which portrays a comparison of the LCR for both appraisals -formerly proposed by Rossignolo, Fethi and Shaban (2012, 2013)- for Basel III and now included in BCBS (2014). It clearly reflects the intentions of the BCBS, i.e. the increase in the SA and a crackdown on the IMA in Columns [4] and [6]. Both approaches provide substantial coverage, notwithstanding which the IMA's MCR comfortably exceeds SA's by a sizeable amount. Therefore, given the characterisation of the SA as a fallback, those precise techniques overcoming the strict validation process appear to have little chance of being applied.

However, the current paper puts forward a straightforward alternative to employ the specifications under the IMA in order to align the incentives to utilise either avenue ${ }^{26}$ -within the boundaries enacted by the BCBS- based on the introduction of multiplicative calibration parameters in $(2.1),(2.3 .1),(2.3 .2)$ and $(2.3 .5)$. Hence, for the IMA, $m_{s}$ and $m_{c}{ }^{*}$ take the following form:

$$
E S=m_{s}\left(E S_{R, S} x \frac{E S_{F, C}}{E S_{R, C}}\right)
$$

and

$$
M C R_{t}=\max \left(I M C C_{t-1} ; m_{c} I M C C_{a v g}\right)
$$

where

$$
m_{c}^{*}=1,5(1+k)
$$

while the SA would feature the sa factor as follows (5.4.4):

$$
\text { Equity Risk Capital }(E R C)=s a\left(\sqrt{\sum_{i=1}^{B} K_{b}^{2}+\sum_{b=1}^{B} \sum_{c>b} \gamma_{b c} S_{b} S_{c}}+K_{\text {Residual }}\right)
$$

Given the pressing concern embodied in the ostensible differences in the level of the MCR, finding a common threshold where the two approaches approximately coincide could in principle dampen the abysmal motivations to apply one or the other. In this vein, the article proposes the calibration of the three parameters across portfolios to minimise the RMSE and $\mathrm{MSE}^{27}$ varying one factor at a time, thus trying to keep the original BCBS structure as unchanged as feasible. Table 18 Panels A and B report the outcome of the exercise, with broadly similar values: holding $m_{s}=1$ and sa=1, mc* should situate in the region of 2.50 ; keeping $m_{c}=1,5$ and sa $=1, m_{s}$ might equal 0.84 and, finally, fixing $m_{c}=1,5$ and $m_{s}=1$, sa could belong to the interval $(1.50 ; 1.54)$.

\footnotetext{
${ }^{26}$ Even though the example is worked out via IMA-EVT, it may be computed using any other scheme passing the validation criteria.

${ }^{27}$ RMSE and MSE stand for Root Mean Squared Error and Mean Squared Error respectively.
} 
The experiment could well be complemented and enhanced with a simulation analysis depicting the level of the MCR and the corresponding LCR varying the calibration parameters $m_{c} *, m_{s}$ and sa simultaneously. This procedure may suggest an idea about the adjustments required to align the incentives, diminish the moral hazard embedded in the current BCBS's proposal and, at the same time, provide enough coverage for market crises of considerable magnitudes. The outcome displayed in Table 19 Panels A, B and $\mathrm{C}$ hints at the fact that equilibrium could be attained by calibrating the aforementioned factors, without compromising the overall coverage. Hence, only for the sake of simplicity and acknowledging the limitations of average values, Columns [18-21] in Panel A indicate that, selecting $m_{c} *=1,80, m_{s}=0,76$ and $s_{a}=1,011$ could deliver approximately $\mathrm{MCR}=0.21$, amounting to $\mathrm{LCR}=1.80$ (i.e., the level of $\mathrm{MCR}$ would withstand more than 1.80 times the worst loss of the 2008 turbulence $^{28}$ ). Table 19, consequently, gives an inkling of the several possibilities that the national supervisors might introduce making use of the flexibility of the parameters guided by the particular considerations verified in their respective countries. Furthermore, it highlights the problems that the proposals could pose to the regulated institutions, both in terms of the excess of the capital buffers and the moral hazard that surges as a consequence of the imbalances between the IMA and SA configurations.

\section{Conclusions and policy implications}

As part of the extensive review of the failures of the regulatory framework in the context of the major crisis of 2007-2008, the BCBS introduced a package of reforms collectively named Basel 2.5 and Basel III to be fully implemented by 2019. However, despite containing stark differences with their predecessor Basel II, they came under scrutiny and are currently subject to ongoing analysis.

One of the stated aims of the proposed reform is to design a new overall approach to risk measurement for the determination of MCR, characterised by the complete overhaul of the SA and the IMA. Under the scheme, the former appears more risk oriented, thus resembling the Markowitz's setting, whereas the latter derives from two major drivers: replacement of VaR for ES and stressed adjustment of the ES-based MCR formula. The BCBS's overt main objective undoubtedly resides in strengthening and increasing the capital base in order to avoid the costly anomalies of former directives. The analysis presented confirms that declared aim, in the sense that Basel IV appears as a move in the right direction: the ES for the IMA and the risk tilt for the SA bring about a substantial overall increase in the MCR. However, as it seems customary for all regulations, it leaves many points to improve, many of which appear underpinned by the results of the study.

In the SA department, the BCBS correctly detected and modified the setting to enact a more risk sensitive appraisal capable of producing higher capital buffers than its predecessor Basel III. Those equity cushions seem almost uniformed across countries and portfolios, therefore facilitating the comparison across jurisdictions, namely another of the BCBS's aim in Basel IV. That homogeneity, arguably achieved through the fixation of the risk weights and correlation parameters across the assets, nevertheless raises lack of efficiency connotations as shown by the substantially high LCR, given the fact that it gives the impression to snub the changing pattern of the correlations among securities. Regarding the IMA, the article points out that the procedure for the validation of the models is excessively restrictive, thus stifling the development of techniques and limiting the scope for innovation. Only the EVT overcomes the subprime crisis unscathed and, although some others like $\mathrm{CV} / \mathrm{GARCH}$-t still manage to put in a reasonable performance, its results are tainted by the numerous Backtesting penalties. Furthermore, the study also detects the presence of inconsistencies, as the most precise techniques may be obliged to

${ }^{28}$ It may be the case that using average values could mask individual glitches for any portfolio. 
Revista Mexicana de Economía y Finanzas Nueva Época, Vol. 14 Primer Número Especial Aniversario, pp. 559-582

DOI: https://doi.org/10.21919/remef.v14i0.423

constitute higher capital levels than less accurate ones.

The interaction between the SA and the IMA posits the most serious concerns. Undoubtedly the BCBS attained its goals of bolstering the capital base by radically revamping both SA and IMA, notwithstanding which the study finds the methodology rather debatable. Although the transformation of the SA into a more risk-sensitive appraisal is healthy, its efficiency remains questionable given that the fixed correlation and risk weights parameters may play to its detriment by neglecting the changing nature of the correlations among assets and, consequently, raising the cost of capital. On the other hand, the IMA is at a (significant) disadvantage as a result of the rise in the capital floor embodied in the SA's values, thus blurring the advantages of the approach and generating a very gloomy perspective for the models as many institutions will undoubtedly carry out the MCR calculations via the SA.

In order to bridge that arguably unintended consequence, the paper puts forward the introduction of calibrating parameters operating as multiplicative factors in the SA and IMA formulas within the structure of Basel IV. This modification would entail greater powers and responsibility to national regulators, who must decide on the appropriate values according to the respective environments. These parameters are developed to align the incentives between the SA and the IMA and, consequently, to restore confidence in market risk models. As was manifested in the study, by determining the right combination of $\mathrm{mc}^{*}, \mathrm{~ms}$ and sa, the supervisors could, in principle, find a common platform upon which a sound and balanced MCR framework could ground providing the correct incentives to apply SA and the accurate IMAs.

The major contributions of the paper root in the ensuing distinct points. Initially, it contains a relatively thorough quantitative idea of the impact that the novel Basel's MCR framework could exert on the banks' capital structure, particularly in the context of emerging stock markets; secondly, it confirms the traces of moral hazard and lack of accuracy incentives for the IMA avenue; thirdly, it highlights that Basel IV upholds the intrinsic imbalances of the dual alternative (SA-IMA) present in Basel II and Basel III, to the point of rendering the IMA somewhat useless and fourthly, it proposes a (simple) sustainable solution likely to reduce the ostensible difference between SA and IMA materialised in the introduction of the calibration parameters $\mathrm{mc}^{*}$, ms and sa within the established framework susceptible of providing adequate capital coverage in the event of major abnormal market slumps.

\section{Referencias}

ACERBI, C., (2004), Coherent representations of subjective risk aversion, in G. Segö (Ed.), Risk Measures for the 21st Century, John Wiley \& Sons, West Sussex, United Kingdom, pp. 147-207.

ACERBI, C., TASCHE, D., (2002), On the Coherence of Expected Shortfall, Journal of Banking and Finance, 26, pp. 1487-1503.

ADRIAN, T., SHIN, H. H., (2013), Procyclical leverage and Value-at-Risk, NBER Working Paper 18943, NBER Working Paper Series, National Bureau of Economic Research, Cambridge, Massachusetts, United States.

ALEXANDER, C., (2008), Market Risk Analysis Volume III: Value-at-Risk Models, John Wiley \& Sons Ltd., The Atrium, Southern Gate, Chichester, West Sussex, United Kingdom.

ARTZNER, P., DELBAEN, F., EBER, K., HEATH, D, (1999), Coherent Measures of Risk, Mathematical Finance, Vol. 9, No. 3, pp. 203-228.

BARONE-ADESI, G., BOURGOIN, F., GIANNOPOUlOS, K., (1998), Don't look back, Risk 11, pp. 100-103.

BASEL COMMITTEE ON BANKING SUPERVISION (2012), Fundamental Review of the Trading Book, Consultative Document, Bank for International Settlements, Basel, Switzerland. 
REMEF (The Mexican Journal of Economics and Finance) Basel IV A gloomy future for Expected Shortfall risk models. Evidence from the Mexican Stock Market

BASEL COMMITTEE ON BANKING SUPERVISION, (2013), Fundamental Review of the Trading Book, Consultative Document, Bank for International Settlements, Basel, Switzerland.

BASEL COMMITTEE ON BANKING SUPERVISION, (2014), Fundamental Review of the Trading Book: Outstanding Issues, Consultative Document, Bank for International Settlements, Basel, Switzerland.

BASEL COMMITTEE ON BANKING SUPERVISION, (1996), Amendment to the Capital Accord to Incorporate Market Risks, Bank for International Settlements, Basel, Switzerland.

BASEL COMMITTEE ON BANKING SUPERVISION, (2004), International Convergence on Capital Measurement and Capital Standards, Bank for International Settlements, Basel, Switzerland.

BASEL COMMITTEE ON BANKING SUPERVISION, (2009), Revisions to the Basel II market risk framework, Bank for International Settlements, Basel, Switzerland.

BERGER, A. N., DE YOUNG, R., FLANNERY, LEE, M. J., ÖZTEKIN, Ö, (2008), How do large banking organizations manage their capital ratios?, Journal of Financial Services Research, 34 (2-3), pp. 123-149.

BERKOWITZ, J., O'BRIEN, J., (2002), How Accurate are Value-at-Risk Models at Commercial Banks?, Journal of Finance, 57, pp. 1093-1112.

BOLLERSLEV, T., (1986), Generalized Autoregressive Conditional Heteroskedasticity, Journal of Econometrics, 31, pp. 307-327.

BOUDOUKH, J., RICHARDSON, M., WHITELAW, R., (1998), The Best of Both Worlds: A Hybrid Approach to Calculating Value-at-Risk, (1998), Risk, Vol. 11, No. 5, pp. 64-67.

CARUANA, J., (2005), Implementation of Basel II, Journal of Financial Markets, Institutions and Instruments, Volume 4, Issue 5, pp. 253-265.

CHRISTOFFERSEN, P. F., (2003), Elements of Financial Risk Management, Academic Press, Elsevier Science, Philadelphia, United States.

COLES, S., (2001), An Introduction to Statistical Modeling of Extreme Values, Springer Series in Statistics, Springer Verlag, London, United Kingdom.

DANIELSSON, J., ZIGRAND, J. P., (2006), On time-scaling and the square-root-of-time rule, Journal of Banking and Finance, 30(10), pp. 2701-2713.

DANIELSSON, J., JORGENSEN, B. N., MANDIRA, S., SAMORODNITSKY G., DE VRIES, C. G. (2005), Subadditivity re-examined: The case for value-at-risk, Discussion Paper 549, Financial Markets Group, London School of Economics and Political Sciences, London, United Kingdom.

DANIELSSON, J., SHIN, H. S, ZIGRAND, J. P., (2009), Risk Appetite and Endogenous Risk, Working paper No. 647, LSE Working Paper Series, London School of Economics, London, United Kingdom.

DEMIRGUC-KUNT, A., DETRAGIACHE, E., and MERROUCHE, O., (2013), Bank Capital: Lessons from the Financial Crisis, Journal of Money, Credit and Banking, Volume 45, Issue 6, pp. 1147-1164.

DOWD, K., (2005), Measuring Market Risk, Second Edition, Wiley series in Frontiers in Finance, John Wiley \& Sons Ltd, Chichester, The Atrium, Southern Gate, Chichester, West Sussex, United Kingdom.

EMBRECHTS, P., KLÜPPELBERG, C., MIKOSCH, T., (1997), Modelling Extremal Events for Insurance and Finance, Springer-Verlag, Berlin Heidelberg, Berlin, Germany.

ENGLE, R. F., 1982. Autoregressive Conditional Heteroskedasticity with Estimates of the Variance of the United Kingdom Inflation, Econometrica, Vol. 50, No. 4, pp. 987-1007.

FÖLlMER, H., SCHIED, A., (2008), Convex Measures of Risk and Trading Constraints, Finance Stoch., 6, pp. 429-447.

HALDANE, A. G., (2011), Capital Discipline, Speech to the American Economists Association, Denver, Colorado, United States.

HELLWIG, M., (1995), Systemic Aspects of Risk Management in Banking and Finance, Swiss Journal of Economics and Statistics, Vol. 131, No. 4/2, pp. 723-737.

HELlWIG, M., (1996), Capital Adequacy Rules as Instruments for the Regulation of Banks, Swiss Journal of Economics and Statistics, Vol. 132, No. 4/2, pp. 609-612.

HELLWIG, M., (2009), Brandbeschleuniger im Finanzsystem, Max Planck Research, Vol. 2, pp. 10-15.

HELTMAN, J, (2014), Ready or Not, Here Comes Basel IV, in American Banker, December 4, 2014.

HERRING, R., (2005), Implementing Basel II: Is the Game Worth the Candle?, Journal of Financial Markets, Institutions and Instruments, Volume 14, Issue 5, pp. 267-287.

KERKHOF, J. and MELENBERG, B., (2004), Backtesting for risk-based regulatory capital, Journal of Banking and Finance, Vol. 28, No. 8, pp. 1845-1865.

MANGANELLI, S., and ENGLE, R. F., (2001), VaR Models in Finance, Working Paper No. 75, European Central Bank Working Paper Series, Frankfurt, Germany.

MARKOWITZ, H., (1952), Portfolio Selection, Journal of Finance, Vol. 7, pp. 77-91.

McNEIL, A. J., SALADIN, T., (1997), The Peaks-Over-Thresholds method for estimating high quantiles of loss distributions, Proceedings of the 28th International ASTIN Colloquium, North Queensland, Australia, pp. 23-43.

McNEIL, A. J., FREY R., EMBRECHTS, P., (2005), Quantitative Risk Management: Concepts, Techniques and Tools, Princeton University Press, Princeton, New Jersey, United States. 
Revista Mexicana de Economía y Finanzas Nueva Época, Vol. 14 Primer Número Especial Aniversario, pp. 559-582

NELSON, D. B., (1991), Conditional Heteroskedasticity in Asset Returns: A New Approach, Econometrica, Vol. 59, pp. 347-370.

PENZA, P. and BANSAL, V. K., (2001), Measuring Market Risk with Value-at-Risk, Wiley Series in Financial Engineering, John Wiley \& Sons, New York, United States.

REISS, R.-D., and THOMAS, M., (2007), Statistical Analysis of Extreme Values with Applications to Insurance, Finance, Hydrology and Other Fields, Birkhäuser Verlag, AG, Berlin, Germany.

REPUlLO, R., and SUAREZ, J., (2013), The Procyclical Effects of Bank Capital Regulation, Review of Financial Studies, 26 (2), pp. 452-490.

ROSSIGNOlO, A. F., FETHI, M. D., SHABAN, M., (2012), Value-at-Risk Models and Basel Capital Charges, Journal of Financial Stability, Vol. 8, Issue 4, pp. 303-319.

ROSSIGNOlO, A. F., FETHI, M. D., SHABAN, M., (2013), Market Crises and Basel Capital Requirements. Could Basel III have been different? Evidence from Portugal, Ireland, Greece and Spain (PIGS), Journal of Banking and Finance, Vol. 37, Issue 5, pp. 1323-1339.

SHIN, H. S., (2008), Risk and Liquidity in a Systemic Context, Journal of Financial Intermediation, Vol. 17, No. 3, pp. 315-329.

TAYLOR, S., (1986), Modeling Financial Time Series, John Wiley \& Sons, New York, United States.

YAMAI, Y., YOSHIBA, Y., (2005), Value-at-Risk versus Expected Shortfall: A Practical Perspective, Journal of Banking and Finance, Vol. 29, pp. 997-1015.

Table 1. Risk Buckets and Economic Sector

\begin{tabular}{|c|c|c|c|}
\hline $\begin{array}{c}\text { Bucket } \\
\text { Number }\end{array}$ & $\begin{array}{c}\text { Company } \\
\text { Size }\end{array}$ & Region & Sector \\
\hline 1 & Large & Emerging markets & Consumer, Utilities \\
\hline 2 & Large & Emerging markets & Telecommunications, Industrials \\
\hline 3 & Large & Emerging markets & Basic materials, Energy \\
\hline 4 & Large & Emerging markets & Financial, Technology \\
\hline 5 & Large & Developed markets & Consumer, Utilities \\
\hline 6 & Large & Developed markets & Telecommunications, Industrials \\
\hline 7 & Large & Developed markets & Basic materials, Energy \\
\hline 8 & Large & Developed markets & Financials, Technology \\
\hline 9 & Small & Emerging markets & All Sectors \\
\hline 10 & Small & Developed markets & All Sectors \\
\hline
\end{tabular}

Table 2. Risk Buckets and Risk Weights

\begin{tabular}{|c|c|}
\hline Bucket N & Risk Weight \\
\hline 1 & $55 \%$ \\
\hline 2 & $60 \%$ \\
\hline 3 & $45 \%$ \\
\hline 4 & $55 \%$ \\
\hline 5 & $30 \%$ \\
\hline 6 & $35 \%$ \\
\hline 7 & $40 \%$ \\
\hline 8 & $50 \%$ \\
\hline 9 & $70 \%$ \\
\hline 10 & $50 \%$ \\
\hline Residual & $70 \%$ \\
\hline
\end{tabular}


Table 3. Correlation parameters within Risk Buckets

\begin{tabular}{|c|c|c|}
\hline Bucket N & Identical Sign & Opposite Sign \\
\hline 1 & $20 \%$ & $10 \%$ \\
\hline 2 & $20 \%$ & $15 \%$ \\
\hline 3 & $25 \%$ & $15 \%$ \\
\hline 4 & $30 \%$ & $20 \%$ \\
\hline 5 & $20 \%$ & $10 \%$ \\
\hline 6 & $30 \%$ & $15 \%$ \\
\hline 7 & $35 \%$ & $20 \%$ \\
\hline 8 & $35 \%$ & $20 \%$ \\
\hline 9 & $15 \%$ & $5 \%$ \\
\hline 10 & $25 \%$ & $10 \%$ \\
\hline Residual & $100 \%$ & $0 \%$ \\
\hline
\end{tabular}

Table 4. Correlation parameters among Risk Buckets

\begin{tabular}{|c|c|c|c|c|c|c|c|c|c|c|}
\hline Buckets & $\mathbf{1}$ & $\mathbf{2}$ & $\mathbf{3}$ & $\mathbf{4}$ & $\mathbf{5}$ & $\mathbf{6}$ & $\mathbf{7}$ & $\mathbf{8}$ & $\mathbf{9}$ & $\mathbf{1 0}$ \\
\hline $\mathbf{1}$ & $100 \%$ & & & & & & & & & \\
\hline $\mathbf{2}$ & $15 \%$ & $100 \%$ & & & & & & & & \\
\hline $\mathbf{3}$ & $15 \%$ & $15 \%$ & $100 \%$ & & & & & & & \\
\hline $\mathbf{4}$ & $15 \%$ & $15 \%$ & $15 \%$ & $100 \%$ & & & & & & \\
\hline $\mathbf{5}$ & $10 \%$ & $10 \%$ & $10 \%$ & $10 \%$ & $100 \%$ & & & & & \\
\hline $\mathbf{6}$ & $10 \%$ & $10 \%$ & $10 \%$ & $10 \%$ & $20 \%$ & $100 \%$ & & & & \\
\hline $\mathbf{7}$ & $10 \%$ & $10 \%$ & $10 \%$ & $10 \%$ & $20 \%$ & $20 \%$ & $100 \%$ & & & \\
\hline $\mathbf{8}$ & $10 \%$ & $10 \%$ & $10 \%$ & $10 \%$ & $20 \%$ & $20 \%$ & $20 \%$ & $100 \%$ & & \\
\hline $\mathbf{9}$ & $10 \%$ & $10 \%$ & $10 \%$ & $10 \%$ & $10 \%$ & $10 \%$ & $10 \%$ & $10 \%$ & $100 \%$ & \\
\hline $\mathbf{1 0}$ & $10 \%$ & $10 \%$ & $10 \%$ & $10 \%$ & $15 \%$ & $15 \%$ & $15 \%$ & $15 \%$ & $15 \%$ & $100 \%$ \\
\hline
\end{tabular}

Table 5. Panel A - Portfolios and risk buckets - Mexico

\begin{tabular}{|c|c|c|c|c|c|c|c|c|}
\hline Equity & Sector & $\begin{array}{l}\text { Market Capitalisation } \\
\text { MXN }\end{array}$ & $\begin{array}{c}\text { FX rate } \\
\text { MXN / USD }\end{array}$ & $\begin{array}{l}\text { Market Capitalisation } \\
\text { USD }\end{array}$ & Size & Bucket Number & \begin{tabular}{|c|}
$\begin{array}{c}\text { Portfolio } 1 \\
\text { Weights }\end{array}$ \\
\end{tabular} & $\begin{array}{c}\text { Portfolio } 2 \\
\text { Weights }\end{array}$ \\
\hline$[1]$ & {$[2]$} & {$[3]$} & {$[4]$} & {$[5]$} & {$[6]$} & {$[7]$} & $|8|$ & {$[9]$} \\
\hline America Móvil & $\begin{array}{l}\text { Telecommunications. } \\
\text { Industrials }\end{array}$ & $1,027,640,270,000.00$ & 14.76 & $69,610,590,881.07$ & Large & 2 & $33.33 \%$ & $26.17 \%$ \\
\hline CEMEX & $\begin{array}{l}\text { Telecommunications. } \\
\text { Industrials }\end{array}$ & $181,434,500,000.00$ & 14.76 & $12,290,062,116.01$ & Large & 2 & $33.33 \%$ & $57.51 \%$ \\
\hline Grupo México & $\begin{array}{c}\text { Basic Materials. } \\
\text { Energy }\end{array}$ & $328,097,810,000.00$ & 14.76 & $22,224,783,406.83$ & Large & 3 & $33.33 \%$ & $16.32 \%$ \\
\hline
\end{tabular}


Table 6.

Panel A - Backtesting - Quantity of exceptions - Confidence level $99 \%$

\begin{tabular}{|c|c|c|c|c|c|c|c|c|c|c|c|c|}
\hline Model & HS & FHS & FHS & FHS & FHS & CV & CV & CV & CV & EVT & Linear & Linear \\
\hline Portfolio & & G-N & G-t & E-N & E-t & G-N & G-t & E-N & E-t & POT & Normal & t \\
\hline Mexico P1 & 18 & 6 & 6 & 9 & 9 & 11 & 6 & 13 & 12 & 0 & 26 & 20 \\
\hline Mexico P2 & 20 & 8 & 8 & 11 & 9 & 12 & 9 & 15 & 9 & 0 & 25 & 20 \\
\hline
\end{tabular}

Panel B - Backtesting - Penalties: increase in add-on $\mathrm{k}$ - Confidence level $99 \%$

\begin{tabular}{|c|c|c|c|c|c|c|c|c|c|c|c|c|}
\hline Model & HS & FHS & FHS & FHS & FHS & CV & CV & CV & CV & EVT & Linear & Linear \\
\hline Portfolio & & G-N & G-t & E-N & E-t & G-N & G-t & E-N & E-t & POT & Normal & t \\
\hline Mexico P1 & $100.00 \%$ & $50.00 \%$ & $50.00 \%$ & $85.00 \%$ & $85.00 \%$ & $100.00 \%$ & $50.00 \%$ & $100.00 \%$ & $100.00 \%$ & $0.00 \%$ & $100.00 \%$ & $100.00 \%$ \\
\hline Mexico P2 & $100.00 \%$ & $75.00 \%$ & $75.00 \%$ & $100.00 \%$ & $85.00 \%$ & $100.00 \%$ & $85.00 \%$ & $100.00 \%$ & $85.00 \%$ & $0.00 \%$ & $100.00 \%$ & $100.00 \%$ \\
\hline
\end{tabular}

Table 7.

Panel A - Backtesting - Quantity of exceptions - Confidence level $99 \%$

\begin{tabular}{|c|c|c|c|c|c|c|c|c|c|c|c|c|}
\hline Model & HS & FHS & FHS & FHS & FHS & CV & CV & CV & CV & EVT & Linear & Linear \\
\hline Portfolio & & G-N & G-t & E-N & E-t & G-N & G-t & E-N & E-t & POT & Normal & t \\
\hline Mexico P1 & 18 & 6 & 6 & 9 & 9 & 11 & 6 & 13 & 12 & 0 & 26 & 20 \\
\hline Mexico P2 & 20 & 8 & 8 & 11 & 9 & 12 & 9 & 15 & 9 & 0 & 25 & 20 \\
\hline \multicolumn{18}{|c|}{ Panel B - Backtesting - Quantity of exceptions - Confidence level $97.50 \%$} & \\
\hline
\end{tabular}

\begin{tabular}{|c|c|c|c|c|c|c|c|c|c|c|c|c|}
\hline Model & HS & FHS & FHS & FHS & FHS & CV & CV & CV & CV & EVT & Linear & Linear \\
\hline Portfolio & & G-N & G-t & E-N & E-t & G-N & G-t & E-N & E-t & POT & Normal & t \\
\hline Mexico P1 & 27 & 16 & 16 & 20 & 19 & 18 & 16 & 18 & 17 & 0 & 34 & 30 \\
\hline Mexico P2 & 32 & 16 & 15 & 20 & 18 & 23 & 20 & 22 & 21 & 0 & 32 & 32 \\
\hline
\end{tabular}


Table 8.

Panel A - Backtesting - Models to be utilised - Confidence level $99 \%$

\begin{tabular}{|c|c|c|c|c|c|c|c|c|c|c|c|c|}
\hline Model & HS & FHS & FHS & FHS & FHS & $\mathrm{CV}$ & $\mathrm{CV}$ & $\mathrm{CV}$ & $\mathrm{CV}$ & EVT & Linear & Linear \\
\hline Portfolio & & G-N & G-t & E-N & E-t & G-N & G-t & E-N & E-t & $\overline{\mathrm{POT}}$ & Normal & $\mathrm{t}$ \\
\hline Mexico P1 & $\mathrm{SA}$ & IMA & $\overline{\mathrm{IMA}}$ & IMA & IMA & IMA & IMA & $\mathrm{SA}$ & IMA & IMA & $\mathrm{SA}$ & $\mathrm{SA}$ \\
\hline Mexico P2 & $\mathrm{SA}$ & IMA & IMA & IMA & IMA & IMA & IMA & $\mathrm{SA}$ & IMA & IMA & $\mathrm{SA}$ & $\mathrm{SA}$ \\
\hline \multicolumn{13}{|c|}{ Panel B - Backtesting - Models to be utilised - Confidence level $97.50 \%$} \\
\hline Model & HS & FHS & FHS & FHS & FHS & CV & CV & CV & $\mathrm{CV}$ & EVT & Linear & Linear \\
\hline Portfolio & & G-N & G-t & $\mathbf{E}-\mathbf{N}$ & E-t & G-N & G-t & E-N & E-t & POT & Normal & t \\
\hline Mexico P1 & $\mathrm{SA}$ & IMA & IMA & IMA & IMA & IMA & $\overline{\mathrm{IMA}}$ & $\mathrm{SA}$ & $\mathrm{IMA}$ & IMA & $\mathrm{SA}$ & $\mathrm{SA}$ \\
\hline Mexico P2 & $\mathrm{SA}$ & IMA & IMA & IMA & IMA & IMA & IMA & $\overline{\mathrm{SA}}$ & IMA & IMA & $\mathrm{SA}$ & $\mathrm{SA}$ \\
\hline
\end{tabular}

Table 9. Summary of Backtesting at $99 \%$ and $97.50 \%$

\begin{tabular}{|c|c|c|c|c|c|c|c|c|c|c|c|c|}
\hline Model & HS & FHS & FHS & FHS & FHS & CV & CV & CV & CV & EVT & Linear & Linear \\
\hline Portfolio & & G-N & G-t & E-N & E-t & G-N & G-t & E-N & E-t & POT & Normal & t \\
\hline Mexico P1 & SA & IMA & IMA & IMA & IMA & IMA & IMA & SA & IMA & IMA & SA & SA \\
\hline Mexico P2 & SA & IMA & IMA & IMA & IMA & IMA & IMA & SA & IMA & IMA & SA & SA \\
\hline
\end{tabular}

Table 10. Panel B - PLAT2 - Quantity of breaches

\begin{tabular}{|c|c|c|c|c|c|c|c|c|c|c|c|c|}
\hline Model & HS & FHS & FHS & FHS & FHS & CV & CV & CV & CV & EVT & Linear & Linear \\
\hline Portfolio & & G-N & G-t & E-N & E-t & G-N & G-t & E-N & E-t & POT & Normal & t \\
\hline Mexico P1 & 2 & 0 & 0 & 2 & 2 & 4 & 3 & 5 & 5 & 0 & 3 & 3 \\
\hline Mexico P2 & 2 & 0 & 0 & 2 & 2 & 4 & 3 & 5 & 5 & 0 & 3 & 3 \\
\hline
\end{tabular}


Table 11.

Panel A - P\&LAT1 - Models to be utilised

\begin{tabular}{|c|c|c|c|c|c|c|c|c|c|c|c|c|}
\hline Model & HS & FHS & FHS & FHS & FHS & CV & CV & CV & CV & EVT & Linear & Linear \\
\hline Portfolio & & G-N & G-t & E-N & E-t & G-N & G-t & E-N & E-t & POT & Normal & t \\
\hline Mexico P1 & IMA & IMA & IMA & IMA & IMA & SA & IMA & SA & SA & IMA & IMA & IMA \\
\hline Mexico P2 & IMA & IMA & IMA & IMA & IMA & SA & IMA & SA & SA & IMA & IMA & IMA \\
\hline Panel B - P\&LAT2 - Models to be utilised \\
\hline Model & HS & FHS & FHS & FHS & FHS & CV & CV & CV & CV & EVT & Linear & Linear \\
\hline Portfolio & & G-N & G-t & E-N & E-t & G-N & G-t & E-N & E-t & POT & Normal & t \\
\hline Mexico P1 & IMA & IMA & IMA & IMA & IMA & SA & IMA & SA & SA & IMA & IMA & IMA \\
\hline Mexico P2 & IMA & IMA & IMA & IMA & IMA & SA & IMA & SA & SA & IMA & IMA & IMA \\
\hline
\end{tabular}

Table 12. Joint analysis P\&LAT

\begin{tabular}{|c|c|c|c|c|c|c|c|c|c|c|c|c|}
\hline Model & HS & FHS & FHS & FHS & FHS & CV & CV & CV & CV & EVT & Linear & Linear \\
\hline Portfolio & & G-N & G-t & E-N & E-t & G-N & G-t & E-N & E-t & POT & Normal & t \\
\hline Mexico P1 & SA & IMA & IMA & IMA & IMA & SA & IMA & SA & SA & IMA & SA & SA \\
\hline Mexico P2 & SA & IMA & IMA & IMA & IMA & SA & IMA & SA & SA & IMA & SA & SA \\
\hline
\end{tabular}

Table 13. Basel IV validation tests - Joint analysis of Steps 1 and 2 - Models to be utilised

\begin{tabular}{|c|c|c|c|c|c|c|c|c|c|c|c|c|}
\hline Model & HS & FHS & FHS & FHS & FHS & CV & CV & CV & CV & EVT & Linear & Linear \\
\hline Portfolio & & G-N & G-t & E-N & E-t & G-N & G-t & E-N & E-t & POT & Normal & t \\
\hline Mexico P1 & SA & IMA & IMA & IMA & IMA & SA & IMA & SA & SA & IMA & SA & SA \\
\hline Mexico P2 & SA & IMA & IMA & SA & IMA & SA & IMA & SA & SA & IMA & SA & SA \\
\hline
\end{tabular}


Table 14. Step 3 - Risk Factor Analysis

\begin{tabular}{|c|c|c|c|}
\hline Portfolio & Factor & Denomination & R2 \\
\hline$[\mathbf{1}]$ & {$[\mathbf{2}]$} & {$[3]$} & {$[4]$} \\
\hline Mexico P1 & IPC & Indice de Precios y Cotizaciones & $72.41 \%$ \\
\hline Mexico P2 & IPC & Indice de Precios y Cotizaciones & $74.68 \%$ \\
\hline
\end{tabular}

Table 15. Basel IV MCR - Internal Models Approach

\begin{tabular}{|c|c|c|c|c|c|c|c|c|c|c|c|c|}
\hline Model & HS & FHS & FHS & FHS & FHS & CV & CV & CV & CV & EVT & Linear & Linear \\
\hline Portfolio & & G-N & G-t & E-N & E-t & G-N & G-t & E-N & E-t & POT & Normal & t \\
\hline$[\mathbf{1}]$ & {$[\mathbf{2}]$} & {$[\mathbf{3}]$} & {$[\mathbf{4}]$} & {$[\mathbf{5}]$} & {$[\mathbf{6}]$} & {$[\mathbf{7}]$} & {$[\mathbf{8}]$} & {$[\mathbf{9}]$} & {$[\mathbf{1 0}]$} & {$[\mathbf{1 1}]$} & {$[\mathbf{1 2}]$} & {$[\mathbf{1 3}]$} \\
\hline Mexico P1 & $30.84 \%$ & $39.81 \%$ & $38.64 \%$ & $43.41 \%$ & $44.94 \%$ & $47.83 \%$ & $31.51 \%$ & $47.64 \%$ & $44.24 \%$ & $44.13 \%$ & $25.64 \%$ & $26.78 \%$ \\
\hline Mexico P2 & $31.03 \%$ & $50.17 \%$ & $49.42 \%$ & $48.99 \%$ & $47.54 \%$ & $50.75 \%$ & $44.06 \%$ & $49.17 \%$ & $45.37 \%$ & $46.83 \%$ & $27.17 \%$ & $28.80 \%$ \\
\hline
\end{tabular}

Table 16.

Panel A - Basel IV MCR - IMA-EVT vs SA - Basel IV vs Basel III

\begin{tabular}{|c|c|c|c|c|c|c|c|c|}
\hline Portfolio & $\begin{array}{c}\text { IMA-EVT } \\
\text { Basel III }\end{array}$ & $\begin{array}{c}\text { IMA-EVT } \\
\text { Basel IV }\end{array}$ & \% Variation & $\begin{array}{c}\text { SA } \\
\text { Basel III }\end{array}$ & $\begin{array}{c}\text { SA } \\
\text { Basel IV }\end{array}$ & \% Variation & $\begin{array}{c}\text { \% Variation } \\
\text { Basel III } \\
\text { IMA-EVT }\end{array}$ & $\begin{array}{c}\text { \% Variation } \\
\text { Basel IV } \\
\text { IMA-EVT }\end{array}$ \\
\hline [1] & {$[\mathbf{2}]$} & {$[\mathbf{3}]$} & {$[\mathbf{4}]$} & {$[\mathbf{5}]$} & {$[\mathbf{6}]$} & {$[\mathbf{7}]$} & $\mathbf{S A}$ & $\mathbf{8}$ \\
\hline Mexico P1 & $80.96 \%$ & $44.13 \%$ & $-45.49 \%$ & $10.50 \%$ & $36.95 \%$ & $251.87 \%$ & $671.02 \%$ & $19.45 \%$ \\
\hline Mexico P2 & $82.20 \%$ & $46.83 \%$ & $-43.03 \%$ & $10.50 \%$ & $35.66 \%$ & $239.62 \%$ & $682.82 \%$ & $31.31 \%$ \\
\hline Average & $81.58 \%$ & $45.48 \%$ & $-44.26 \%$ & $10.50 \%$ & $36.31 \%$ & $245.75 \%$ & $676.92 \%$ & $25.38 \%$ \\
\hline Std. Dev. & $0.88 \%$ & $1.91 \%$ & & $0.00 \%$ & $0.91 \%$ & & & \\
\hline
\end{tabular}


Panel B - Basel IV second best IMA CV/GARCH-t vs SA

\begin{tabular}{|c|c|c|c|c|c|}
\hline Portfolio & $\begin{array}{c}\text { MCR } \\
\text { CV-GARCH-t }\end{array}$ & $\begin{array}{c}\text { MCR } \\
\text { SA }\end{array}$ & \% Variation & $\begin{array}{c}\text { MCR } \\
\text { Basel IV }\end{array}$ & $\begin{array}{c}\text { Official } \\
\text { Appraisal }\end{array}$ \\
\hline$[\mathbf{1}]$ & {$[\mathbf{2}]$} & {$[\mathbf{3}]$} & {$[\mathbf{4}]$} & {$[\mathbf{5}]$} & {$[\mathbf{6}]$} \\
\hline Mexico P1 & $31.51 \%$ & $36.95 \%$ & $-14.71 \%$ & $36.95 \%$ & SA \\
\hline Mexico P2 & $44.06 \%$ & $35.66 \%$ & $23.54 \%$ & $44.06 \%$ & IMA \\
\hline Average & $37.79 \%$ & $36.31 \%$ & $4.42 \%$ & $40.51 \%$ & \\
\hline
\end{tabular}

Table 17. MCR and LCR - IMA-EVT vs SA

\begin{tabular}{|c|c|c|c|c|c|}
\hline \multicolumn{1}{|c|}{ Table 17. MCR and LCR - IMA-EVT vs SA } \\
\hline Portfolio & Maximum loss & IMA-EVT & IMA-EVT & SA & SA \\
\hline & Year 2008 & MCR & LCR & MCR & LCR \\
\hline [1] & {$[\mathbf{2}]$} & {$[3]$} & {$[4]$} & {$[5]$} & {$[6]$} \\
\hline Mexico P1 & $-10.86 \%$ & $44.13 \%$ & $406.28 \%$ & $36.95 \%$ & $340.12 \%$ \\
\hline Mexico P2 & $-12.18 \%$ & $46.83 \%$ & $384.41 \%$ & $35.66 \%$ & $292.75 \%$ \\
\hline
\end{tabular}

Table 18.

Panel A - The optimisation problem: RMSE

\begin{tabular}{|c|c|c|c|c|}
\hline Factor & mc* $^{*}$ & ms & sa & RMSE \\
\hline mc* $^{*}$ & 2.51146 & 1.00000 & 1.00000 & 0.47519 \\
\hline $\mathbf{m s}$ & 1.50000 & 0.83715 & 1.00000 & 0.47519 \\
\hline sa & 1.50000 & 1.00000 & 1.54273 & 0.36276 \\
\hline
\end{tabular}

Panel B - The optimisation problem: MSE

\begin{tabular}{|c|c|c|c|c|}
\hline Factor & mc* $^{*}$ & ms & sa & MAE \\
\hline $\mathrm{mc}^{*}$ & 2.50345 & 1.00000 & 1.00000 & 0.59235 \\
\hline $\mathrm{ms}$ & 1.50000 & 0.84015 & 1.00000 & 0.59235 \\
\hline $\mathrm{sa}$ & 1.50000 & 1.00000 & 1.50316 & 0.51414 \\
\hline
\end{tabular}


Table 19.

Panel A - Sensitivity analysis - Selected examples

\begin{tabular}{|c|c|c|c|c|c|c|c|c|c|c|c|c|}
\hline Portfolio & IMA-EVT & IMA-EVT & SA & SA & IMA-EVT & IMA-EVT & SA & SA & IMA-EVT & IMA-EVT & SA & SA \\
\hline Appraisal & $\mathbf{m c}=\mathbf{1 . 4 0}$ & $\mathbf{m s}=\mathbf{0 . 6 8}$ & $\mathbf{s a}=\mathbf{0 . 8 9}$ & $\mathbf{s a}=\mathbf{0 . 8 9}$ & $\mathbf{m c}=\mathbf{1 . 5 0}$ & $\mathbf{m s}=\mathbf{0 . 7 0}$ & $\mathbf{s a}=\mathbf{0 . 9 2}$ & $\mathbf{s a}=\mathbf{0 . 9 2}$ & $\mathbf{m c}=\mathbf{1 . 6 0}$ & $\mathbf{m s}=\mathbf{0 . 7 2}$ & $\mathbf{s a}=\mathbf{0 . 9 5}$ & $\mathbf{s a}=\mathbf{0 . 9 5}$ \\
\hline & $\mathbf{L C R}$ & $\mathbf{M C R}$ & $\mathbf{L C R}$ & $\mathbf{M C R}$ & $\mathbf{L C R}$ & $\mathbf{M C R}$ & $\mathbf{L C R}$ & $\mathbf{M C R}$ & $\mathbf{L C R}$ & $\mathbf{M C R}$ & $\mathbf{L C R}$ & $\mathbf{M C R}$ \\
\hline$[\mathbf{1}]$ & {$[\mathbf{2}]$} & {$[\mathbf{3}]$} & {$[\mathbf{4}]$} & {$[\mathbf{5}]$} & {$[\mathbf{6}]$} & {$[\mathbf{7}]$} & {$[\mathbf{8}]$} & {$[\mathbf{9}]$} & {$[\mathbf{1 0}]$} & {$[\mathbf{1 1}]$} & {$[\mathbf{1 2}]$} & {$[\mathbf{1 3}]$} \\
\hline Mexico P1 & 1.3142 & 0.1457 & 2.6748 & 0.2906 & 1.4220 & 0.1545 & 2.8830 & 0.3132 & 1.5601 & 0.1695 & 3.1124 & 0.3381 \\
\hline Mexico P2 & 1.2199 & 0.1486 & 2.3023 & 0.2804 & 1.3454 & 0.1639 & 2.4814 & 0.3023 & 1.4761 & 0.1798 & 2.6789 & 0.3263 \\
\hline Average & 1.2808 & 0.1472 & 2.4886 & 0.2885 & 1.3837 & 0.1592 & 2.6822 & 0.3078 & 1.5181 & 0.1747 & 2.8957 & 0.3322 \\
\hline
\end{tabular}

Panel B - Sensitivity analysis - Selected examples (cont.)

\begin{tabular}{|c|c|c|c|c|c|c|c|c|c|c|c|c|}
\hline Portfolio & IMA-EVT & IMA-EVT & SA & SA & IMA-EVT & IMA-EVT & SA & SA & IMA-EVT & IMA-EVT & SA & SA \\
\hline Appraisal & $\mathrm{mc}=1.70$ & $\mathrm{~ms}=0.74$ & $\mathrm{sa}=\mathbf{0 . 9 8}$ & $\mathrm{sa}=\mathbf{0 . 9 8}$ & $\mathrm{mc}=1.80$ & $\mathrm{~ms}=0.76$ & $\mathrm{sa}=1.01$ & $\mathrm{sa}=\mathbf{1 . 0 1}$ & $\mathrm{mc}=1.90$ & $\mathrm{~ms}=0.78$ & $\mathrm{sa}=1.04$ & $\mathrm{sa}=1.04$ \\
\hline & LCR & MCR & LCR & MCR & LCR & MCR & LCR & MCR & LCR & MCR & LCR & MCR \\
\hline & {$[14]$} & {$[15]$} & {$[16]$} & {$[17]$} & {$[18]$} & [19] & {$[20]$} & {$[21]$} & {$[22]$} & {$[23]$} & {$[24]$} & {$[25]$} \\
\hline Mexico P1 & 1.7037 & 0.1851 & 3.3501 & 0.3639 & 1.8526 & 0.2012 & 3.2656 & 0.3938 & 2.0070 & 0.2180 & 3.2978 & 0.4267 \\
\hline Mexico P2 & 1.6120 & 0.1964 & 2.8835 & 0.3512 & 1.7529 & 0.2135 & 3.1206 & 0.3801 & 1.8990 & 0.2313 & 3.3807 & 0.4118 \\
\hline Average & 1.6579 & 0.1908 & 3.1168 & 0.3576 & 1.8028 & 0.2074 & 3.3731 & 0.3870 & 1.9530 & 0.2247 & 3.3654 & 0.4193 \\
\hline
\end{tabular}

Panel C - Sensitivity analysis - Selected examples (cont.)

\begin{tabular}{|c|c|c|c|c|c|c|c|c|}
\hline Portfolio & IMA-EVT & IMA-EVT & SA & SA & IMA-EVT & IMA-EVT & SA & SA \\
\hline Appraisal & $\mathbf{m c}=\mathbf{2 . 0 0}$ & $\mathbf{m s}=\mathbf{0 . 8 0}$ & $\mathbf{s a}=\mathbf{1 . 0 7}$ & $\mathbf{S a}=\mathbf{1 . 0 7}$ & $\mathbf{m c}=\mathbf{2 . 1 0}$ & $\mathbf{m s}=\mathbf{0 . 8 2}$ & sa=1.10 & Sa=1.10 \\
\hline & $\mathbf{L C R}$ & $\mathbf{M C R}$ & $\mathbf{L C R}$ & $\mathbf{M C R}$ & $\mathbf{L C R}$ & $\mathbf{M C R}$ & $\mathbf{L C R}$ & $\mathbf{M C R}$ \\
\hline & {$[\mathbf{2 6}]$} & {$[\mathbf{2 7}]$} & {$[\mathbf{2 8}]$} & {$[\mathbf{2 9}]$} & {$[\mathbf{3 0}]$} & {$[\mathbf{3 1}]$} & {$[\mathbf{3 2}]$} & {$[\mathbf{3 3}]$} \\
\hline Mexico P1 & 2.1668 & 0.2354 & 4.2404 & 0.4606 & 2.3332 & 0.2533 & 4.5638 & 0.4957 \\
\hline Mexico P2 & 2.0502 & 0.2497 & 3.6498 & 0.4446 & 2.2065 & 0.2688 & 3.9282 & 0.4785 \\
\hline Average & $\mathbf{2 . 1 0 8 5}$ & $\mathbf{0 . 2 4 2 6}$ & $\mathbf{3 . 9 4 5 1}$ & $\mathbf{0 . 4 5 2 6}$ & $\mathbf{2 . 2 6 9 3}$ & $\mathbf{0 . 2 6 1 1}$ & $\mathbf{4 . 6 0 0 0}$ & $\mathbf{0 . 4 8 7 1}$ \\
\hline
\end{tabular}

